\title{
THE EFFECT OF FAMILIARIZATION ON TEMPORAL ASPECTS OF TURN-TAKING: A PILOT STUDY*
}

\author{
TEKLA ETELKA GRÁCZI ${ }^{\mathrm{a}}$ - SAROLTA BATA ${ }^{\mathrm{b}}$ \\ ${ }^{a}$ Research Institute for Linguistics, Hungarian Academy of Sciences \\ Benczúr u. 33., H-1068 Budapest, Hungary \\ graczi@nytud.hu \\ ${ }^{\mathrm{b}}$ Department of Phonetics, Eötvös Loránd University \\ Múzeum krt. 4/A, H-1088 Budapest, Hungary \\ batasarolta@gmail.com
}

\begin{abstract}
The organization of conversations with respect to turn-taking and back-channeling is a well-established field of research. Suprasegmental features governing these phenomena have been analyzed regarding both speech production and perception. The present study aims to analyze an interpersonal factor, the process of familiarization and the nature of relationship of the speakers and its effects on the properties of turn-taking and back-channeling. The reasons and temporal organization of turn-taking and back-channeling were analyzed in the initial and final parts of three-member conversations of Hungarian speakers of diverse relationships. The patterns of reasons, the forms of turn-taking and the occurrence of back-channeling turned out to show particular effects of the relationship/familiarity of the speakers.
\end{abstract}

Keywords: turn-taking, familiarization, accommodation, temporal factors, conversation

\section{Introduction}

\subsection{Conversation theories}

In conversations, two or more people are involved as interlocutors. Each person must have the right to participate in the discourse. This requires a cooperation of the interlocutors (Grice 1975). This cooperation results in turns and instances of turn-taking/yielding. Turns are the parts of speech events during which one of the interlocutors speaks until (s)he passes

* The research reported here was supported by the Hungarian National Scientific Research Fund (OTKA), No. 78315. 
over - or another interlocutor takes over - the right for speech. In principle, one speaker speaks at a time and the other interlocutor(s) play(s) a hearer's role during this period. This means that both overlapping speech and longer pauses are to be avoided (Sacks et al. 1974, 706).

Several studies have been carried out to investigate gestures and phonetic cues of turn-taking. The relevant investigations examined turn-taking in terms of the acoustic and perceptual properties of speech (e.g., Stephens-Beattie 1986; Ruiter et al. 2006). Among prosodic cues, pitch (e.g., Cutler-Pearson 1986; Wells-Peppé 1996), voice quality (e.g., Ogden $2001 ; 2004$ ), and the temporal organization of turn-taking (WilsonWilson 2005; Tanaka 2006; Stivers et al. 2009) have been examined.

Sacks et al. (1974), who were among the first researchers dealing with the phenomenon, proposed a model in which turn-taking occurs at 'transition relevance points', the end points of syntactically and semantically defined units, and is governed by the aim of minimizing gaps and overlaps. Duncan (1972) found that turn-taking is governed by phonemic cues, and varies with the formality of the discourse (e.g., in terms of the ratio of overlapping speech).

Weilhammer and Rabold (2003) analyzed durational aspects of the various types of turn-taking. They found no significant differences between the duration of between-turn pauses and overlapping parts of turn-taking in Japanese and in American English, but these durations were statistically different in German. The distribution of their data contradicts Sacks et al.'s (1974) findings. In Weilhammer and Rabold's study, back-channeling mostly appeared as a short period of overlap. On the basis of these results they assumed that in cases where the triggering properties could be traced, back-channeling was mostly governed by prosodic, syntactic, and semantic cues. Beattie et al. (1982) found that a pitch fall signals turn-yielding for hearers. In an interview with Margaret Thatcher, the interviewer interrupted Mrs. Thatcher more often at points where her fundamental frequency decreased quickly than at other points. Maclay and Osgood (1959) as well as Beattie (1977) found that the kind of pause also plays a significant role in turn-taking. Filled pauses signal an attempt of continuation, while unfilled occurrences trigger turn-taking. Therefore unfilled turn-internal pauses tend to appear after filled ones. However, speakers are usually unaware of their pauses: they cannot tell what kind of pause they have held and for how long (Gósy 2004). Local-Kelly (1986) made a contribution on turn-yielding and turn-holding pauses. The pauses showed differences in breathing and the phonetic char- 
acteristics of their filled part. Stephens and Beattie (1986) found that drawl and perceived pause duration are also important indicators of turnyielding. Ford and Thompson (1996) found that in cases of longer pauses usually the former speaker began to talk again. Several studies examined the gestural indication of turn-taking and turn-yielding (e.g., Beattie 1979; Cassell et al. 1999; Kendon 2002; Lerner 2003). Various factors of turn organization have a common impact on conversation (e.g., FordThompson 1996; Wennerstrom-Siegel 2003). Although turn-taking and turn-yielding show universal characteristics, they are language-dependent and also culturally determined. Stivers et al. (2009) analyzed the timing of turn-taking in ten languages, looking for universal properties. They found a strong universal basis of turn-taking behavior: the duration of overlaps in conversation and between-turn pauses showed similar distributions in various cultures. The objective values of duration of both overlaps and pauses turned out to be relatively short (most frequently between 0 and $200 \mathrm{~ms}$ ). Shigemitsu (2005) analyzed between-turn pauses and their interpretations by the interlocutors depending on culture. In her experiment two Japanese-American conversations and a Chinese-American one involving four interlocutors were recorded. Shigemitsu found that Chinese and Japanese speakers prefer longer pauses to change the topic while Americans prefer rapid turn-takings and a higher speech-to-pause ratio.

Overlapping speech is considered to be an "error" in the conversation by several authors and it is assumed that speakers tend to avoid or break off simultaneous speaking (e.g., Sacks et al. 1974). Phenomena like uh-huh, yeah, I see, etc. are often considered as back-channeling with the function of signaling the listener's attention rather than the intention of turn-taking (cf. Taboada 2006; Schegloff 1982), and therefore they are to be analyzed separately from "real" turn-takings (e.g., Duncan 1972). Ward and Bayyari (2006) investigated the phenomena triggering backchanneling in conversations in Arabic. Pitch movements (frequency drop, jagged contour), pause length, utterance length and the distance from the last instance of back-channeling were found to be phonetic primes for the phenomenon.

The patterns of turn-taking proved to be dependent on several properties of the conversation and the interlocutors participating in it. Ten Bosch et al. (2005) found that overlapping speech (also called 'interruption') is more frequent in conversations between males than in those between female speakers. In addition, this study proved that speakers accommodate their turn-taking behavior to their interlocutor's. 
Some of the earlier investigations on Hungarian conversations were carried out in order to analyze the characteristics of within-turn and between-turn pauses. Markó (2006) found in her four-member conversation analysis that within-turn pauses tend to be about three times shorter than between-turn pauses. The pragmatic and phonetic characteristics of (less frequent) longer within-turn pauses signaled the speaker's turn-holding intentions. The speaker's turn part preceding a pause was semantically and/or pragmatically unfinished, the pitch of the turn increased, and/or the pause appeared partly as a filled pause. Evellei (2009) suggested that pauses without the function of breathing and those that occurred at syntactically completed points triggered turn-taking more frequently than any other types of pauses.

Bata (2009) analyzed discourses with elderly and with young people. The discourses were parts of the Hungarian spontaneous speech database (Gósy 2008). The interlocutors were the interviewer (a young woman), the interviewee, and a third person (one of the interviewer's young female colleagues). Several characteristics of the conversations, including the total length of the conversations, and the ratio of overlapping speech, showed dependency on the interviewee's age. Duration of between-turn pauses and turn-takings from the interviewee varied according to the age of the interviewee and showed the consequences of some other factors affecting the conversations, like the interviewee's "disposition to speak".

\subsection{Accommodation theories}

During communication and social interaction, accommodation (or divergation) appears to a certain degree in all cases and it is governed by several factors of the situation. There are a number of accommodation theories and they consider different factors to be the (main) governing ones. Bell (1984) proposed an audience design that considers both the size of the audience and the participants' role (like addressee, hearer) as the governing factor of accommodation. Giles and Smith (1979) analyzed accommodation in terms of sociopsychological concepts. The paper describes speakers' accommodation or divergation mainly by means of four sociopsychological theories. Giles developed his proposal by analyzing several sets of empirical data (e.g., 1977; 1979) that provided a basis for his 'communication accommodation theory' (CAT). The basic idea of this theory is that speakers shift their style, vary the characteristics of their speaking, in order to reach their goals. Speakers may converge more or 
less directly to their speech partners or diverge from them (Bourhis 1979; Drake 1980; Eisikovits 1987; Meyerhoff 1998, etc.). The theory claims that speakers accommodate to the speech partner's known or (in the case of strangers) unknown but presupposed speech characteristics.

Douglas-Cowie (1978) analyzed interviews where the interviewer and the interviewee were complete strangers. Her results suggested that a style shift would take place during the interviews by means of increasing vernacular characteristics. These results could be explained as due to the familiarization of the speakers. The question is whether the factors of familiarization during turn-takings can be expressed in terms of phonetic properties.

The aim of our study was to carry out a preliminary investigation concerning the effects of interlocutors' familiarity on the organization of conversations. Our questions were (i) how intimacy (here: friendship) affects the turn-taking structures of conversations, and (ii) how the structures of turn-taking change as the interlocutors' level of familiarity grows. The study analyzes three main features of conversations: reasons for turn-taking, forms of turn-taking/yielding, and their temporal aspects.

\section{Subjects, method, material}

For the purposes of the present study, we have used the BEA (Spoken Speech Corpus - Beszélt nyelvi adatbázis), recorded at the Research Institute for Linguistics of the Hungarian Academy of Sciences (Gósy 2008). Interviewees for the recordings are recruited by informing them on the main goals of the database, but they are not informed on the parts of the recordings. The speakers are volunteers. Four conversations of this database were analyzed. These conversations take place almost at the end of the recordings, which means that the interviewer and the interviewee have had time to get accommodated to each other to a certain degree. The interviewer is the same 27-year-old female speaker in all recordings. The interviewees are four male speakers. Two of them were close friends of the interviewer while two of them had never met her before. The two male friends will be called "friends" while the two formerly unknown speakers will be called "strangers" henceforth. The interviewees' age was 38 and 44 (friends); 39 and 45 (strangers). The third person was always a complete stranger for the interviewee when she/he entered into the conversation. The third person was not the same in all the four conversations, a 27-year-old female colleague of the interviewer participated in 
three conversations while a male colleague of the interviewer attended the fourth one (where the interviewee was a 45-year-old stranger). The appearance of the third person results in a situation where the two original speakers (the interviewer and the interviewee) are not as much a pair of strangers at the beginning of the three-participant conversation as the third one is for the interviewee at the same time since the third person is situationally a stranger. The beginning and the end of the conversations were selected in order to study the degrees of accommodation of the speakers and the easement of the effect of the interview-situation preceding the conversations. Four-minute samples of the conversations were selected both from their initial and from final phases. The intervals between the two samples differed across recordings. These intervals were $5^{\prime} 55^{\prime \prime}$ and $23^{\prime} 3^{\prime \prime}$ in the conversations with the two strangers while they were $11^{\prime} 6^{\prime \prime}$ and $10^{\prime} 10^{\prime \prime}$ with the two friends. The conversations begin with the interviewees' opinion/experience on a topic chosen by the interviewer, but all three speech partners can alter it during the discourse like in everyday conversations. The starting topics of the four conversations were different. In a conversation with a stranger and one with a friend, the interviewer asked for their opinion on the public transport of Budapest. In the conversation with the other stranger, the basic topic was school children's rights and obligations, while in the fourth discourse (with a friend) it was the interviewee's job.

The intentions with which the speakers started to speak (the reason for turn-taking), as well as the time organization of turns (overlapping, appearance of between-turn pauses, immediate starting: 'turn forms' henceforth), were grouped. The frequency of the various intentions of the speakers to start speaking and that of the turn forms during the first and last four minutes of the conversations was calculated. The duration of the between-turn pauses was also analyzed.

The analysis was carried out using Praat 5.0 (Boersma-Weenink 2005). The four conversations were annotated by the authors. The annotation consisted of various levels. Each speaker was annotated on a seperate tier containing both the speaker's utterances (in a quasi-phonetic transcription) and pauses. The duration of pauses was marked; the label indicated the type of the pause: whether it was a within- or a betweenturn pause. The within-turn pause labels included an identity code of the speaker. In a fourth tier, turn-taking was marked. These labels contained a code of the former speaker(s), a code of the following speaker(s), a code of the following speaker's reason for turn-taking: (i) answering a ques- 
tion, (ii) questioning, (iii) sharing an opinion, (iv) repeating the other's utterance, (v) finishing the other's utterance, (vi) back-channeling, and the type/form of turn-taking. In some cases the reasons for speaking could not be given by means of a single category. For example, there were cases in our material where turn-taking started with humming (the sequence ühüm 'uh-huh'). These cases show that the person who is going to speak agrees with the current speaker's opinion and wants to add something to the foregoing or wants to add a new point to the conversation. These and similar cases were annotated using a code for "more than one reasons for speaking". Vocal events where no turn-taking or -yielding intention could be detected were considered as back-channeling by the authors. This was supposed in cases in which the "back-channeling person" showed attention or agreement (no disagreement was shown in this way) by a short and mostly quiet vocal sign. This sign was either humming or a verbal expression or both. Longer forms of showing agreement invariably appeared in verbal expressions, and resulted in the former speaker's turn-yielding. The type of turn-taking was labeled as (i) speaking after a pause, (ii) beginning to speak before the other speaker ends his/her turn, (iii) simultaneous turn, (iv) beginning immediately at the end of the former speaker's turn or (v) starting in the same moment. 'Beginning before the former speaker ends his/her turn' and 'simultaneous turn' were separated on the basis of the continuation of the turns by the speakers. In cases where the second speaker ended his/her turn later, the turn was considered as beginning before the former speaker ended his/her turn; and cases where the second speaker ended his/her turn first and the former speaker kept on speaking were considered as simultaneous turns. Cases in which there was no analyzable pause between the end of the former speaker's turn and the beginning of the next speaker's turn were considered as beginning immediately at the end of the former speaker's turn. Cases where there was no analyzable timing difference between the beginning of two speakers' turns were considered as beginning at the same moment. The shortest detected between-turn pause was $13.5 \mathrm{~ms}$. In cases where turn-taking was accompanied by a between-turn pause, the start of the label was set at the start of the pause and the end of the label was set at the end of the pause. In the remaining cases, where any kind of simultaneous speaking occurred, the start of the label was set at the start of the speaker's turn who began his/her turn later or, in the cases of beginning at the same moment, the start of the label was set at the beginning of the simultaneous turns. The end of these labels was set at 
the point where the speaker ending his/her turn first, ended his/her turn. So, the labels of the simultaneous turns showed the duration of simultaneous speaking. Data of the conversations were retrieved automatically by a Praat-script written by the authors. The script listed the text of the labels of the within-turn pauses and the turn-takings, and it also calculated the length of the labels. These duration data could be considered as the duration of the pauses and the simultaneous turn-parts.

Statistical analysis was carrried out by ANOVA with Tukey post hoc tests using SPSS 13.0. The confidence level was set at 95\%. The statistical analysis could not be carried out in each case since the number of the phenomena analysed limited the possibility of statistical analysis.

\section{Results}

The four conversations, as expected, showed both similar and different features. Figure 1 illustrates the speaking time ratio of the three speakers in the conversations.

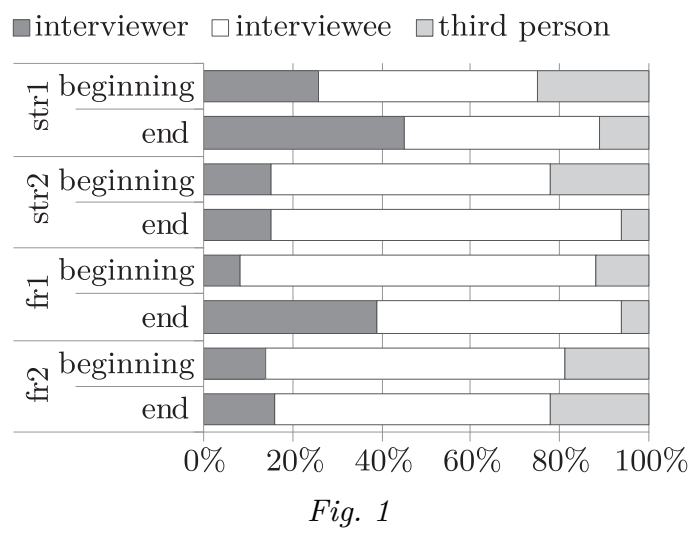

Speaking time ratio of the interlocutors during the conversations $(\mathrm{fr}=$ friend, $\operatorname{str}=$ stranger $)$

The interviewee holds the floor in the highest percentage in all cases during the first four minutes (between $44 \%$ and $80 \%$ ), while the interviewer's speaking time ratio increases up to nearly the same percentage as that of the interviewee's speaking time in two cases during the last four minutes. The third person's speaking time ratio seems to decrease between the initial and the final phase of the conversations. The interviewee's speaking 
time ratio slightly decreases in two conversations while it decreases by almost $32 \%$ of the original speaking time during the beginning phase in one conversation, and increases by $21 \%$ in the fourth conversation.

\subsection{Reason for speaking}

The pragmatic reason of beginning to speak was analyzed depending on the context of the turn-takings. The possible reasons were divided into two major groups: back-channeling (like $u h$-huh, surprise, agreeing, etc.) and (intended) turn-taking in order to take the floor. The latter was further divided into six subgroups like questioning, answering, sharing one's opinion, continuing or ending a former turn of one's own, finishing the other's turn and repeating a part of the other's utterance as a sign of agreement. The ratio of back-channeling compared to turn-taking is higher in most cases. In a conversation with a stranger and in another conversation with a friend back-channeling is more frequent than turn-taking (by $100 \%$ and $20 \%$, respectively) during the first four minutes. Backchanneling is less frequent than turn-taking in the other two discourses (by $20 \%$ and $35 \%$ ). During the last four minutes back-channeling is less frequent than turn-taking only in one of the four conversations (by $9 \%$ ) while it is more frequent than turn-taking (by 19 to 26\%) in the other three conversations.

The number of turn-takings differs across conversations. Their number is relatively low in the conversations with the strangers during the first four minutes (12 and 5), while this phase of the conversations with the friends contains 24 and 46 turn-takings. The comparison of the number of turn-takings between the beginning and the final phases of the interviews show different tendencies. In the conversations with the strangers their number increases by a large amount (2.3 and 5.4 times more frequent occurrences), while this number in one of the conversations with the friends increases in a lower ratio (1.4) and decreases in the other one (by 13.1\%). Despite the divergent tendencies of the conversations, the number of turn-takings is still higher $(35,40)$ in the last four minutes of those with friends than it is in this phase with the strangers $(27$, 26). These facts can be explained by the organizational differences of the initial and final phases of the conversations. At the beginning of the conversations, the interviewer starts with one or more questions of a topic, and all the three speakers answer it/them. In some cases the organization of the conversation changes abruptly while in other cases this change 
is slower; as a result, the initial phase adopts the nature of interviews. The shift from dialogues to conversation progresses and can clearly be seen when comparing the first and the last phases of the conversation (Figure 2).

(i) In the conversation with one of the strangers, questioning $(25.0 \%$ of all turn-takings), answering ( $16.7 \%$ of all turn-takings), sharing one's opinion ( $41.7 \%$ of all turn-takings) and finishing the other's utterance (16.7\% of all turn-takings) appeared during the first four minutes. During the last four minutes sharing one's own opinion became more frequent ( $70.4 \%$ of all turn-takings) as opposed to the ratio of other reasons that strongly decreased (3.7\% and $11.1 \%$ of all turn-takings). A "new" reason for intending to speak appears during the last for minutes of the discourse: the intention to finish a formerly started turn of one's own. This type of turn occurs in $7.4 \%$ of all turn-takings. The reason for these organizational patterns may be the shift mentioned above. The conversation becomes more vivid, and interruptions become more frequent.

(ii) In the conversation with the other stranger, questioning ( $60 \%$ of all turn-takings) and answering (40\% of turn-takings) occur during the first part of the conversation. During the last four minutes of the discourse, questioning and answering do not appear at all, but sharing an opinion of one's own occurs in $46.2 \%$ of all turn-takings. Finishing the other's utterance $(19.2 \%)$, repeating it for agreeing $(11.5 \%)$ and continuing an earlier turn (19.2\%) appear as well. In some cases intention to speak seems to have several reasons $(3.8 \%)$. There can be various reasons to finish the others' utterances. It can show agreement, or help the other person to recover from a spot of disfluency. These patterns may share the same reasons as those in the conversation analyzed above.

(iii) In the two conversations with friends, the first four minutes showed different turn-taking patterns compared to the recordings with the strangers. In one of them, all reasons for turn-taking appeared. Despite this difference, the most frequent reasons were questioning (25.0\%) and answering (33.3\%). In this conversation, continuing an earlier turn was also frequent $(16.7 \%)$. These organizational differences may be explained by the difference of the relations of the participants. The interviewer and the interviewee knew each other and knew each other's opinion, plans, etc. concerning the topic; therefore, it was not necessary to go into details when talking to a friend. Despite the organizational difference of the conversations during the first four minutes, comparing the first and the last four minutes in this discourse shows a change similar to that of the conversations with strangers (described above). The most frequent reasons for turns among friends are different from those in the conversations with strangers. Questioning $(25.7 \%)$, answering (11.9\%) and sharing an opinion of one's own $(51.4 \%)$ appear the most frequently. A new phenomenon characterizing this conversation is that during the final phase even the interviewee raises questions.

(iv) In the fourth discourse, the first four and the last four minutes show almost identical patterns. All of the reasons for turn-taking can be seen, but the most frequent ones are questioning $(28.3 \%, 30.0 \%)$, answering $(15.2 \%, 15 \%)$, sharing an opinion of one's own $(30.4 \%, 32.5 \%)$ and continuing an earlier turn of one's own $(19.6 \%, 15.0 \%)$. The increased frequency of giving one's own opinion and continuing an earlier turn during the first four minutes may be caused by the difference of the relations. 


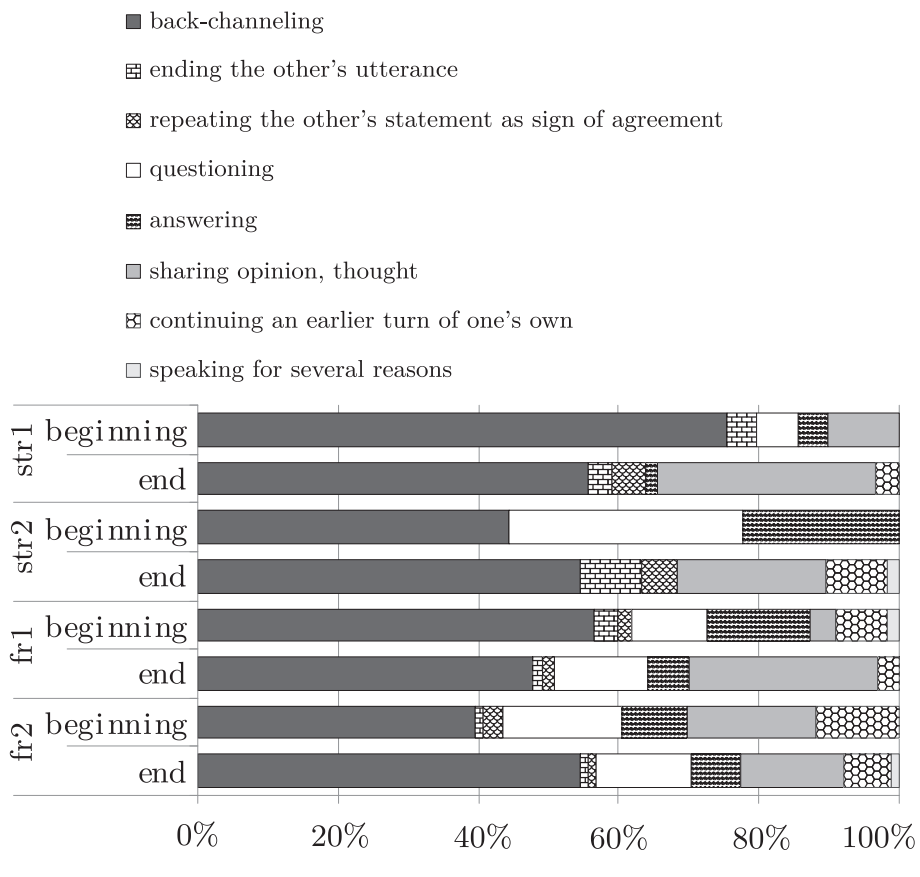

Fig. 2

Reasons of speech events

\subsection{Turn forms}

Analyzing the ways of exercising the right for speaking shows that there are five different types: (i) a pause occurs between the turns, (ii) the speaker starts speaking before the end of the other's turn, which results in overlapping, and the second speaker takes the turn, (iii) the speaker who wants to take the turn is speaking simultaneously with the first speaker for a while (henceforth: short simultaneous turn), but then the first speaker carries on; (iv) in some cases the second speaker begins to speak immediately at the end of the first speaker's turn, so no pauses or overlapping periods occur, (v) two speakers start speaking at the same moment. Case (v) is of course a subtype of any other of the former four cases, as there always exists a former speaker.

The present study analyzes the speaking form characteristics of backchanneling and turn-taking, and the differences between the first and the last four minutes of the conversations. 
Figure 3 shows the frequency of turn forms in back-channeling and turn-taking. The most frequent turn forms were simultaneous turn, starting before the end of the other's utterance, and starting after a pause. The remaining two forms appeared in less than $6 \%$ of the cases. The reason may be that these forms appear by accident, as it were. Simultaneous turns were more frequent in back-channeling (64.7\%) than in turn-taking $(12.6 \%)$. Starting after a pause is also a very frequent turn form. It occurs in $19.8 \%$ of back-channeling and $37.2 \%$ of turn-taking. Although earlier studies (e.g., Sacks et al. 1974) claim that speakers tend to avoid and break off overlapping, in our samples the beginning of a turn before the end of the other's turn occurred in $39.5 \%$ of all turn-taking. This means that simultaneous turns (12.6\%) and starting to speak before the other has finished $(39.5 \%)$ amount to a definitely high ratio of turn-taking in comparison to average findings. In the following analysis we will discuss the three most frequent turn forms.

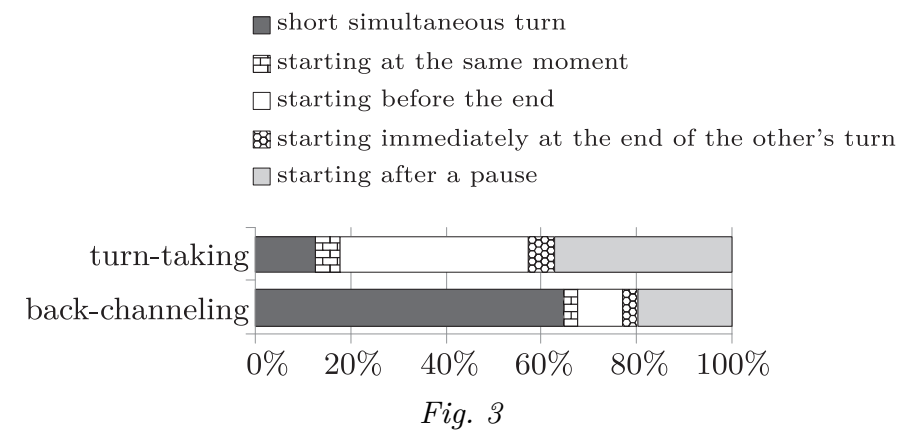

The distribution of turn forms in back-channeling and turn-taking

Figure 4 shows the distribution of reasons of speech events and turn forms. Turn-taking with the second speaker beginning his/her turn after a pause is rare in cases where (s)he finishes the first speaker's utterance, shows agreement by repeating part of the utterance or goes on with a former turn of his/her own $(7.1 \%, 18.2 \%, 21.7 \%$, respectively). In these cases both kinds of overlapping speech appears in more than $20 \%$ of the turns. The most frequent turn form begins before the end of the other's utterance. In cases of questioning and answering the most frequent form is where a pause appears between the turns $(63.4 \%, 58.6 \%$, respectively).

The higher frequency of non-overlapping speech in these cases might be caused by diverse reasons. In cases where the second speaker wants to share his/her opinion with the others, short simultaneous turns appear 


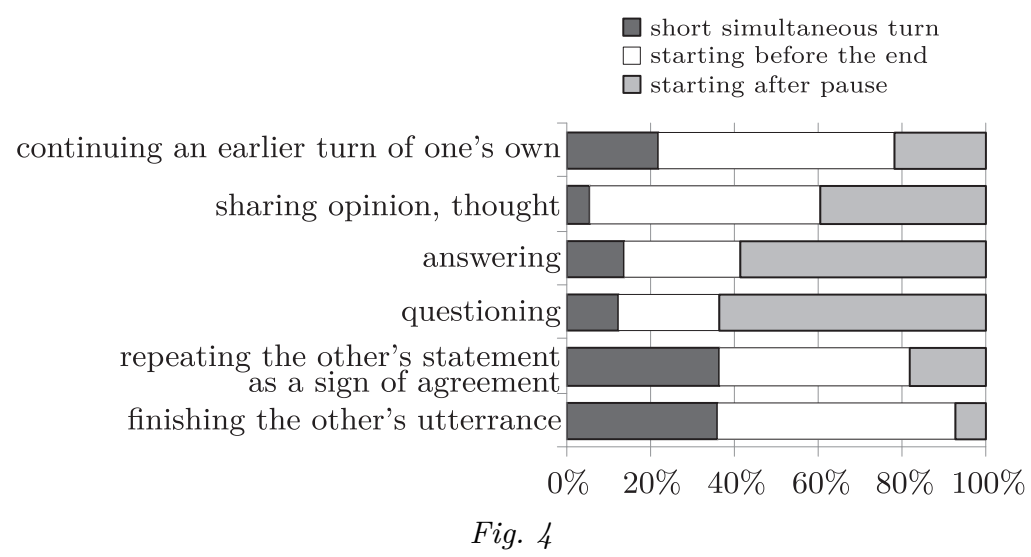

The distribution of turn forms in the different reasons of turn-takings

(5.4\%), starting before the other ends his/her turn is the most frequent (54.8\%), and starting after a pause occurs in $21.7 \%$ of the cases. The increased frequency of overlapping speech may be caused by different reasons in the different cases. When sharing an opinion or idea or continuing an earlier turn of his/her own, the speaker may have formed his/her thoughts already before or during the other speaker's turn, a fact that may result in the fast reaction. In cases of continuing an earlier turn of his/her own, the speaker has been interrupted by another speaker in most of the cases. This may have an effect on the organization of turns as well. When repeating part of the other's utterance or finishing it, the intention of the speaker is to help the former speaker or to show agreement that is closer to back-channeling than to other kinds of intentions. This might result in a fast and short speech turn. The different turn-patterns of questioning and answering might be caused by different reasons as well. In the case of answering, the speaker may need some time to arrange his/her thoughts about the topic involved in the question. In the case of questioning, on the other hand, several reasons might occur. In our corpus this means helping the interlocutors (to continue the conversation part of the interview where the speakers have different roles) and the expression of interest as well.

Figure 5 shows the distribution of the analyzed turn-forms during the beginning and the end of the conversations. Non-overlapping speech is more frequent $(66.7 \%, 100 \%)$ during the beginning of the conversations with strangers than overlapping, while the first four minutes of the conversations with friends does not show any difference between the ratio 
of overlapping and non-overlapping speech $(54.2 \%, 50.5 \%)$. The ratio of non-overlapping speech decreases in each conversation: it occurs in $51.9 \%$ and $30.8 \%$ in the last four minutes of the conversations with the strangers and $42.9 \%$ and $42.5 \%$ in the final phase of those with the friends. The two types of overlapping speech [(i) the first speaker goes on/short simultaneous turn, (ii) the second speaker continues after the overlapping period/starting before the end] occur in different ratios in the conversations. The second type is more frequent during the beginning of the conversations with the friends $(41.7 \%, 43.9 \%)$ than the first type $(4.2 \%$, $12.2 \%$ ) and than it is during the first part in the conversations with the strangers $(18.2 \%, 0 \%)$. The ratio of starting before the end of the other's turn is higher during the final phase of the conversations (39-56\%), than during the beginning. The type of short simultaneous turn is less frequent (by $75-82 \%$ ) during the last four minutes of the conversations than during the initial phase, except in conversation str2, where they appear in the same ratio (39.1\%).

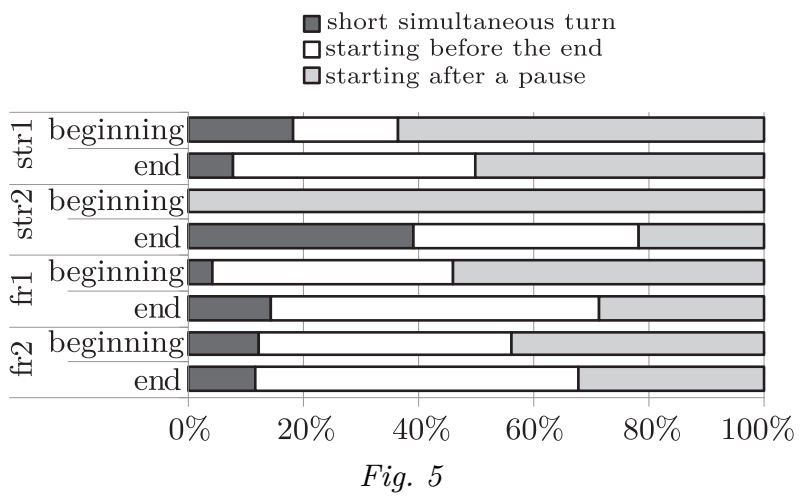

Distribution of turn forms at the beginning and during the end of the conversations (The ratio is given in the percentage of all turn-takings of the conversation analyzed) $($ str $=$ stranger, $\mathrm{fr}=$ friend $)$

\subsection{Duration of overlapping, and between-turn pauses}

Turn forms show various kinds of dependency on the interlocutors' degree of familiarity both in back-channeling and turn-taking. When backchanneling, the form is overlapping between $61 \%$ and $100 \%$, mostly (54$88 \%$ ) constituting a simultaneous turn. In cases of turn-taking, the ratio of overlapping to non-overlapping increases in all conversations. Comparing the first four minutes of all conversations, starting after a pause is 
more frequent in the discourses with strangers (strangers: 63.6\%, 100\% vs. friends: $54.2 \%, 43.9 \%$ ), while comparing the final four minutes this difference depends rather on the nature of discourse itself (strangers: $50.0 \%$, $21.7 \%$ vs. friends: $28.6 \%, 32.4 \%$ ). The lower ratio of non-overlapping in the conversations with friends during the first four minutes compared to those with strangers, and during the last part of all conversations compared to the first parts, may be caused by the familiarity of the speakers.

Figure 6 shows the duration of instances of back-channeling that appeared simultaneously with the actual speaker's speaking.

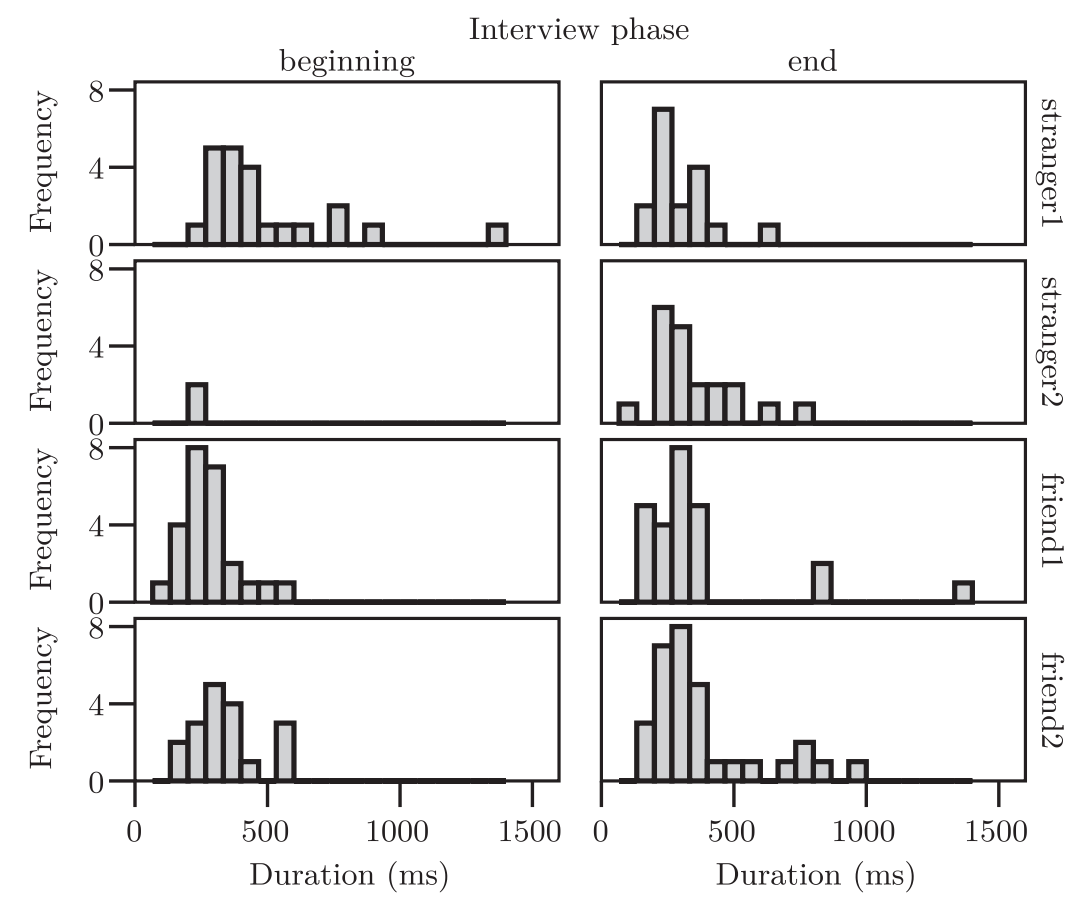

Fig. 6

Duration of the overlapping instances of back-channeling during the beginning and the end of the conversations

In one of the conversations with a stranger, simultaneous back-channeling was longer (mean: $489.0 \mathrm{~ms}, \mathrm{SD}=258.2 \mathrm{~ms}$ ) than in the other three discourses (mean: $307.6 \mathrm{~ms} / \mathrm{SD}=115.2 \mathrm{~ms}, 223.5 \mathrm{~ms} / \mathrm{SD}=0.0 \mathrm{~ms}, 283.5 \mathrm{~ms}$ / $\mathrm{SD}=110.1 \mathrm{~ms}, 343.3 \mathrm{~ms} / \mathrm{SD}=118.2 \mathrm{~ms})$. This difference was significant between this and a conversation with a friend (ANOVA: $F(3,66)=5.960$, 
$p=0.001$; Tukey post-hoc test $p=0.001$ ). This difference disappears at the end of the discourses, the average durations of the simultaneous instances of back-channeling are between 307.6 and $377.7 \mathrm{~ms}(F(3,92)=$ $0.432, p=0.730)$. However, the standard deviation of the data shows a wide difference (110.1-273.0 ms). We suppose that this similarity is caused by the phenomenon of back-channeling itself. As in most cases - as also mentioned in the literature (e.g., Duncan 1972) - back-channeling itself signals that the back-channeling person does not intend to take the turn, but rather shows his/her attention or agreement. This kind of non-verbal but vocalic signal can be considered as non-interrupting up to a certain length. This durational tendency of back-channel signals may be caused by their functions and the sign types used. Most of the back-channel signals were humming showing attention and agreement. The duration of these kinds of humming were found to be $214-630 \mathrm{~ms}$ $($ mean $=357.9 \mathrm{~ms})$ and between 249 and $558 \mathrm{~ms}($ mean $=351.0 \mathrm{~ms})$ in an elicitation experiment, while spontaneous samples were about $20 \%$ shorter (Markó 2005).

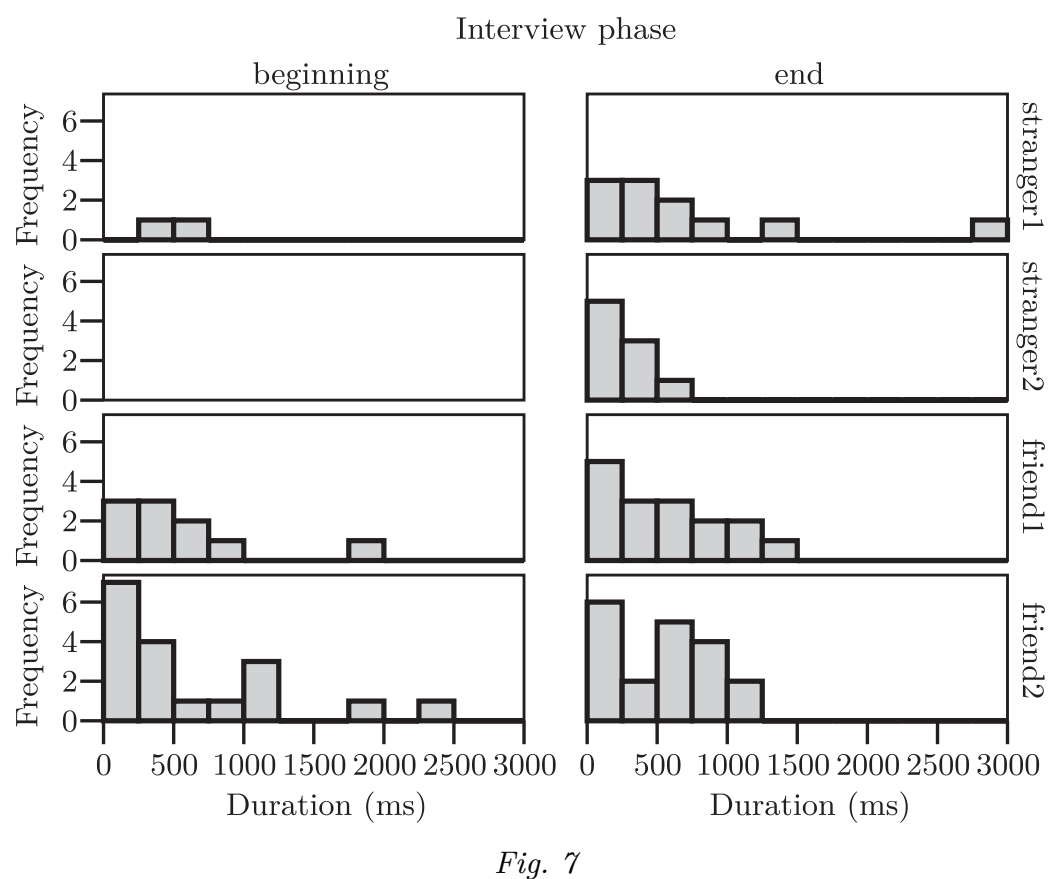

Duration of the overlapping parts of turn-takings where the speaker starts his/her turn before the end of the former speaker's turn 
In cases of overlapping speech that is not back-channeling, not only the type of the turn (whether it is co-operation or competition) but also the duration of the simultaneous portion may be important in conversations. Simultaneous turns indicate either that the second speaker could not take the turn or that their intention was not competitive at all. Therefore the duration of simultaneous turns may show high variability. In our speech samples it varied in the range of 149.5 to $1564.8 \mathrm{~ms}$. The average duration was $600.1 \mathrm{~ms}$ with a standard deviation of $404.1 \mathrm{~ms}$. Differences of this kind among the four conversations were not analyzed because of their low occurrence. The type of overlapping speech in which the speaker begins his/her turn before the end of the other's turn is quite similar to the simultaneous turns. In these cases the second speaker continues his/her turn, and the former speaker becomes a listener. Similar speech intentions may appear in these cases as well. This phenomenon is more frequent, but it occurs mostly (more than 10 times in the samples analyzed) with three intentions: questioning, answering, and continuing an earlier turn of one's own. During the first four minutes of the conversations, this kind of turn beginning can be analyzed only in the two recordings with friends (Figure 7). Although the duration tends to be lower (under $1000 \mathrm{~ms}$ ), sometimes longer overlaps appear as well. This type of overlapping becomes more frequent during the last four minutes of the speech samples. Their duration tends to be lower in these cases as well: there was but a single case where it was longer than $1500 \mathrm{~ms}$. In this case the interviewee was talking, and the interviewer wanted to add her own example to the story. She began to speak simultaneously with the interviewee, who wanted to end his own turn as well. Both spoke to the end of their thoughts, that is, both of them completed their respective turns.

Figure 8 (overleaf) shows the distribution of between-turn pauses in the first four and last four minutes of the conversations. During the first four minutes the average duration of between-turn pauses was $365.3 \mathrm{~ms}$ with a standard deviation of $338.1 \mathrm{~ms}$. During the last four minutes of the conversations this mean was $494.3 \mathrm{~ms}$ with a standard deviation of $390.4 \mathrm{~ms}$. Figure 8 shows that short pauses (under $1000 \mathrm{~ms}$ ) are more preferred during the first four minutes. During the last four minutes pauses longer than $1000 \mathrm{~ms}$ appeared as well. Each conversation showed the same organizational tendency, but the results are not analyzed separately, as there were only a few between-turn pauses per conversation parts. 


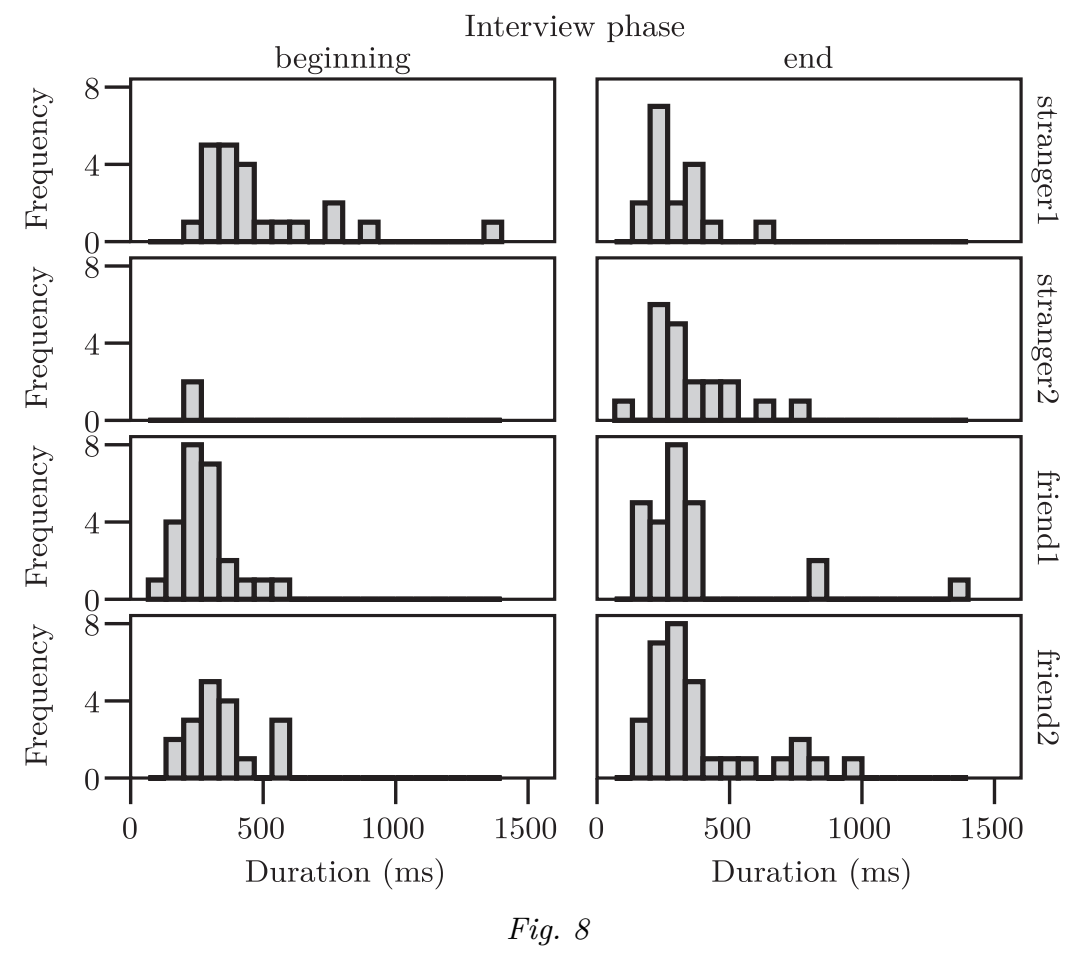

Duration of between-turn pauses during the beginning and the end of the conversations

\section{Concluding remarks}

The present study was carried out to analyze the characteristics of conversations from the aspect of speakers' familiarity. The beginning and the end of four conversations were compared to describe the speakers' familiarization during the discourse. In two speech samples, the interviewees had already known the interviewer before the recording, they were closely related, while in the other two discourses the interviewee and the interviewer met each other for the first time at the recording session. Although these data show only tendencies because of the fact that the conversation was part of an interview (see, e.g., Llisterri 1992), the results can help us consider the situational factors affecting the structure of conversations. Some of the results showed familiarity dependency; others are to be explained by other factors. 
Turn forms and the speakers' intention about turn-taking were found to be interrelated. In cases of back-channeling, overlapping forms occurred more often than non-overlapping realizations. This distribution proved to be independent of familiarity. However, in cases of other intentions where real turn-taking occurred, the turn form depended on familiarization as well as on the speaker's reason for turn-taking. In general, the speakers began their turns before the former speaker ended his/her own turn more frequently in the conversations with friends, and it became more frequent during the last minutes of the conversations compared to the beginning phases.

Overlapping appeared in a relatively high ratio in all conversations, similarly to the results of former investigations on Hungarian $(73 \%$ in Evellei 2009), while the duration of between-turn pauses tended to be shorter than what was found in the former literature on Hungarian (Markó 2006). This difference can be explained by a number of factors, e.g., the difference of the situation of the conversations.

Similarly to turn forms, the reasons for turn-taking also differed in the conversations with friends compared to those with strangers. Sharing an opinion of one's own was more frequent in the former than in the latter, and became more frequent towards the end of the conversations than it was at the beginning.

Between-turn pauses were longer during the last four minutes of the conversations than during the first part. This tendency may have various reasons. Familiarization may allow longer silent periods when the conversations get closer to the end; also, the participants seemed to be tired of thinking and therefore they preferred longer pauses, and the speakers needed more time to seek new ideas on the topic.

Although the samples analyzed allow us to draw only conservative and careful conclusions, the data show clear tendencies that match our everyday experience of conversation organization, and therefore they can help us conceive further hypotheses and studies.

The results raise further questions, like the analysis of type of familiarity (e.g., parent(s) and child(ren); different types of couples; employeremployee) or factors governing the mode of familiarity (e.g., length of conversation, personal characteristics, topic). 


\section{References}

Bata, Sarolta 2009. A társalgás fonetikai jellemzőinek alakulása a beszélők életkorának függvényében [Phonetic properties of conversations depending on participants' age]. In: Tamás Váradi (ed.): III. Alkalmazott Nyelvészeti Doktorandusz Konferencia [Proceedings of the Third Conference of PhD-students in Applied Linguistics], 3-13. Research Institute for Linguistics, HAS, Budapest.

Beattie, Geoffrey 1977. The dynamics of interruption and the filled pause. In: The British Journal of Social and Clinical Psychology $16: 283-4$.

Beattie, Geoffrey 1979. Planning units in spontaneous speech: Some evidence from hesitation in speech and speaker gaze direction in conversation. In: Linguistics $17: 61-78$.

Beattie, Geoffrey W.-Anne Cutler-Mark Pearson 1982. Why is Mrs. Thatcher interrupted so often? In: Nature $300: 744-7$.

Bell, Alan 1984. Language style as audience design. In: Language in Society $1: 145-204$.

Boersma, Paul-David Weenink 2005. Praat: Doing phonetics by computer. (Version 5.0.1) [Computer program].

Bourhis, Richard Y. 1979. Language in ethnic interaction: A social psychological approach. In: Howard Giles-Bernard Saint-Jacques (eds): Language and ethnic relations, 117-41. Pergamon Press, Oxford.

Cassell, Justine-Obed E. Torres - Scott Prevost 1999. Turn taking vs. discourse structure: How best to model multimodal conversation. In: Yorick Wilks (ed.): Machine conversations, 143-54. Kluwer, Dordrecht.

Cutler, Anne-Mark Pearson 1986. On the analysis of prosodic turn-taking cues. In: Catherine John-Levis (ed.): Intonation of discourse, 139-55. Croom Helm, London.

Douglas-Cowie, Ellen 1978. Linguistic code-switching in a Northern Irish village: Social interaction and social ambition. In: Peter Trudgill (ed.): Sociolinguistic patterns in British English, 37-51. Edward Arnold, London.

Drake, Glendon F. 1980. The social role of slang. In: Howard Giles - William P. Robinson - Philip M. Smith (eds): Language: Social psychological perspectives. Selected papers from the First International Conference on Social Psychology and Language, 63-70. Pergamon Press, Oxford.

Duncan, Starkey 1972. Some signals and rules for taking speaking turns in conversations. In: Journal of Personality and Social Psychology 28:286-8.

Eisikovits, Edina 1987. Sex differences in inter-group and intra-group interaction among adolescents. In: Anne Pauwels (ed.): Women and language in Australian and New Zealand society, 45-58. Australian Professional Publications, Sydney.

Evellei, Kata Dóra 2009. A szünetek szerepe a társalgásban. Különös tekintettel a beszélöváltásokra [The role of various types of pauses in conversation, especially with respect to turn-taking]. BA thesis, ELTE, Budapest.

Ford, Cecilia-Sandra A. Thompson 1996. Interactional units in conversation: Syntactic, intonational, and pragmatic resources for the management of turns. In: Elinor Ochs-Emanuel A. Schegloff-Sandra A. Thompson (eds): Interaction and grammar, 134-84. Cambridge University Press, Cambridge.

Acta Linguistica Hungarica 57, 2010 
Giles, Howard 1977. Social psychology and applied linguistics: Toward an integrative approach. In: I.T.L. Review of Applied Linguistics $33: 27-42$.

Giles, Howard 1979. Sociolinguistics and social psychology. In: Giles - Clair (1979, 1-20).

Giles, Howard - Robert N. St. Clair (eds) 1979. Language and social psychology. Blackwell, Oxford.

Giles, Howard-Philip Smith 1979. Accommodation theory: Optimal levels of convergence. In: Giles - Clair (1979, 45-65).

Gósy, Mária 2004. Fonetika, a beszéd tudománya [Phonetics, the science of speech]. Osiris Kiadó, Budapest.

Gósy, Mária 2008. Magyar spontánbeszéd-adatbázis - BEA [Hungarian spontaneous speech corpus - BEA]. In: Mária Gósy (ed.): Beszédkutatás 2008 [Speech research 2008], 194-207. MTA Nyelvtudományi Intézet, Kempelen Farkas Beszédkutató Laboratórium, Budapest.

Grice, H. Paul 1975. Logic and conversation. In: Peter Cole-Jerry L. Morgan (eds): Syntax and semantics, vol. 3: Speech acts, 41-58. Academic Press, New York.

Kendon, Adam 2002. Some uses of the head shake. In: Gesture 2:147-82.

Lerner, Gene H. 2003. Selecting next speaker: The context-sensitive operation of a context-free organization. In: Language in Society 32 : 177-201.

Llisterri, Joaquim 1992. Speaking styles in speech research. Paper presented at the ELSNET/ ESCA/SALT Workshop on Integrating Speech and Natural Language. Dublin, Ireland, 15-17 July 1992.

(http://liceu.uab.es/ joaquim/publicacions/SpeakingStyles_92.pdf; retrieved: 13 October 2009).

Local, John - John Kelly 1986. Projection and "silences": Notes on phonetic and conversational structure. In: Human Studies $9: 185-204$.

Maclay, Howard - Charles E. Osgood 1959. Hesitation phenomena in spontaneous English speech. In: Word $15: 19-44$.

Markó, Alexandra 2005. A spontán beszéd néhány szupraszegmentális jellegzetessége. Monologikus és dialogikus szövegek összevetése, valamint a hümmögés vizsgálata [Some suprasegmental properties of spontaneous speech. A comparison of monologues and conversations, and an analysis of humming]. Doctoral dissertation, Eötvös Loránd University, Budapest.

Markó, Alexandra 2006. Beszélőváltások a társalgásban [Turn-takings in conversations]. Paper presented at the Ninth Workshop on Psycholinguistics and Applied Linguistics, Balatonalmádi, 21-4 May 2006. (http://www.fonetika.nytud.hu/letolt/ma_2.pdf; retrieved: 1 December 2006).

Meyerhoff, Miriam 1998. Accommodating your data: The use and misuse of accommodation theory in sociolinguistics. In: Language and Communication 18:205-25.

Ogden, Richard 2001. Turn transition, creak and glottal stop in Finnish talk-in-interaction. In: Journal of the International Phonetics Association 31:139-52.

Ogden, Richard 2004. Non-modal voice quality and turn-taking in Finnish. In: Elizabeth Couper-Kuhlen-Cecilia E. Ford (eds): Sound patterns in interaction (Typological Studies in Language 62), 29-62. John Benjamins, Amsterdam \& Philadelphia. 
Ruiter, Jan Peter de-Holger Mitterer-Nicolas J. Enfield 2006. Projecting the end of a speaker's turn: A cognitive cornerstone of conversation. In: Language 82 : 515-35.

Sacks, Harvey-Emanuel A. Schegloff-Gail Jefferson 1974. A simplest systematics for the organization of turn-taking for conversation. In: Language 50:696-735.

Schegloff, Emanuel A. 1982. Discourse as an interactional achievement: Some uses of 'uh huh' and other things that come between sentences. In: Deborah Tannen (ed.): Analyzing discourse: Text and talk, 71-93. Georgetown University Press, Washington DC.

Shigemitsu, Yuka 2005. Different interpretations of pauses in natural conversation and Japanese, Chinese and Americans. Technical report, Academic Reports Fac. 9 Eng. Tokyo Polytech. Univ. Vol. 28 No.2.

Stephens, Jane-Geoffrey Beattie 1986. On judging the ends of speaker turns in conversation. In: Journal of Language and Social Psychology 5 : 119-34.

Stivers, Tanya - Nicolas J. Enfield - Penelope Brown - Christina Englert-Makoto Hayashi-Trine Heinemann - Gertie Hoymann - Federico Rossano - Jan Peter de Ruiter-Kyung-Eun Yoon-Stephen C. Levinson 2009. Universals and cultural variation in turn-taking in conversation. In: Proceedings of the National Academy of Sciences of the United States of America 106:10587-92.

Taboada, Maite 2006. Spontaneous and non-spontaneous turn-taking. In: Pragmatics $16: 329-60$.

Tanaka, Hiroko 2006. Turn projection in Japanese talk-in-interaction. In: Research on Language and Social Interaction $33: 1-38$.

Ten Bosch, Louis - Nelleke Oostdijk-Lou Boves 2005. On temporal aspects of turn taking in conversational dialogues. In: Speech Communication 47:80-6.

Ward, Niegel - Yaffa A. Bayyari 2006. A case study in the identification of prosodic cues to turn-taking: Back-channeling in Arabic. In: INTERSPEECH 2006 : 1257-910.

Weilhammer, Karl-Susen Rabold 2003. Durational aspects in turn-taking. In: MariaJosep Solé-Daniel Recasens-Joachim Romero (eds): Proceedings of the 15th International Congress of Phonetic Sciences (Barcelona, 3-9 August 2003), 21458. Causal Productions, Barcelona.

Wells, Bill-Sue Peppé 1996. Ending up in ulster: prosody and turn-taking in English dialects. In: Elizabeth Couper-Kuhlen-Margret Selting (eds): Prosody in conversation, 57-101. Cambridge University Press, Cambridge.

Wennerstrom, Ann-Andrew F. Siegel 2003. Keeping the floor in multiparty conversations: Intonation, syntax, and pause. In: Discourse Processes 36:77-107.

Wilson, Margaret - Thomas P. Wilson 2005. An oscillator model of the timing of turntaking. In: Psychonomic Bulletin and Review 12:957-68. 